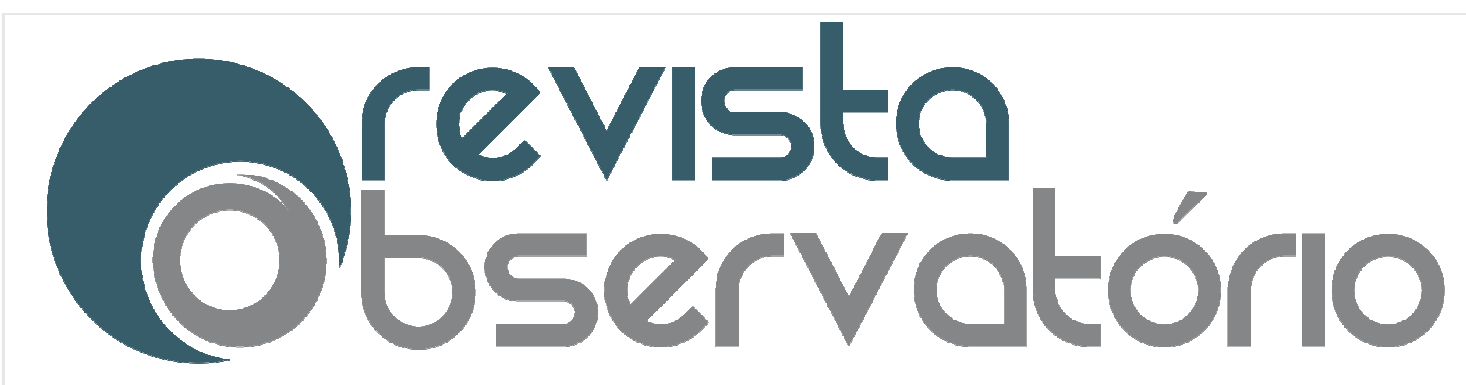

\section{A INTERNET COMO FERRAMENTA DE APRENDIZAGEM E DIFUSÃO CULTURAL E LINGUÍSTICA DAS MULHERES SURDAS}

THE INTERNET AS A LEARNING TOOL AND CULTURAL AND LINGUISTIC DIFFUSION FOR DEAF WOMEN

LA INTERNET COMO HERRAMIENTA DE APRENDIZAJE Y DIFUSIÓN CULTURAL Y LINGÜÍSTICA DE LAS MUJERES SURDAS

\author{
Ana Luisa Gediel ${ }^{1}$ \\ Mylene Mayara Santos Dias ${ }^{2}$ \\ Thayane Fraga De Paula, 4
}

\title{
RESUMO
}

O artigo pauta-se no desenvolvimento de um estudo etnográfico acerca da saúde de um grupo de mulheres Surdas e do uso de Tecnologias de Informação

\footnotetext{
${ }^{1}$ Graduada em Antropologia e doutora em Antropologia Social pela Universidade Federal do Rio Grande do Sul (UFRGS). Professora do Departamento de Letras, Universidade Federal de Viçosa (UFV), vinculada ao Programa de Pós-Graduação em Letras, linha Estudos Linguísticos e ao Mestrado Interinstitucional em Antropologia Social PPGAS/Museu Nacional e UFV (MINTER). E-mail: ana.gedielufv@gmail.com.

${ }^{2}$ Graduada em Enfermagem, Universidade Federal de Viçosa (UFV) e bolsista FAPEMIG de iniciação científica da pesquisa. In Memoriam.

${ }^{3}$ Graduada em Enfermagem, Universidade Federal de Viçosa (UFV) e bolsista FAPEMIG de iniciação científica da pesquisa. E-mail: thayanefraga23@gmail.com.

${ }^{4}$ Endereço de contato das autoras (correio): Universidade Federal de Viçosa. Programa de PósGraduação em Letras. Avenida Peter Henry Rolfs, s/n - Campus Universitário, Viçosa - MG, CEP: 36570-900, Brasil.
} 


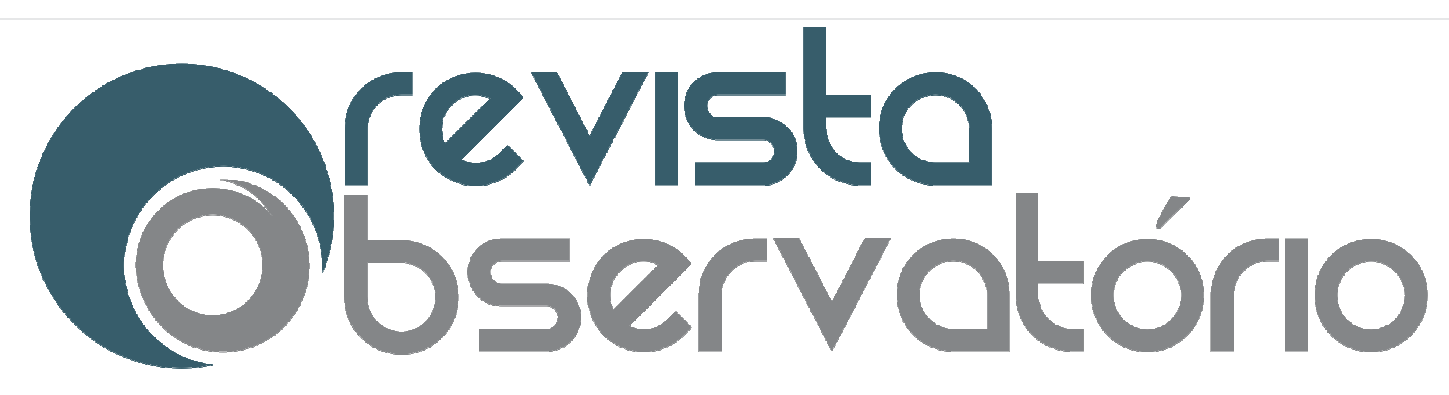

e Comunicação (TICs) como agency, ou seja, como instrumento de busca de entendimento acerca de sua saúde corporal e de sua sexualidade. Neste processo verificamos por meio das redes sociais que o uso da LIBRAS (Língua Brasileira de Sinais) e a identificação com o ser Surdo caracterizam-se de forma positiva, pois contrapõem-se à visão da surdez como deficiência. Por fim, demonstramos a importância do uso das tecnologias como meio de acesso aos conhecimentos sobre a própria saúde, que nem sempre chegam às mulheres Surdas a partir dos profissionais da saúde.

PALAVRAS-CHAVE: Mulheres Surdas; LIBRAS; Tecnologias; Acessibilidade.

\section{ABSTRACT}

The article is based on the development of an ethnographic study considering a group of Deaf women and the use of Information and Communication Technologies (ICTs) as an agency to get information about women's health. The technologies work as an instrument to search for understanding about their corporal health and their sexuality. In this process, we verified through social networks that the use of LIBRAS (Brazilian Sign Language) and the identification with the Deaf person are characterized in a positive way, as they oppose the view of disability. Finally, we demonstrated the importance of the use of technologies as an instrument of access to knowledge about health, which does not always is offered for Deaf women by health professionals.

KEYWORDS: Deaf Women; LIBRAS; Technologies; Accessibility.

\section{RESUMEN}

El artículo se pauta en el desarrollo de un estudio etnográfico acerca de la salud de un grupo de mujeres Surdas y del uso de Tecnologías de Información y Comunicación (TICs) como agencia, o sea, como instrumento de búsqueda de entendimiento acerca de su salud corporal y De su sexualidad. En este proceso verificamos por medio de las redes sociales que el uso de la LIBRAS (Lengua Brasileña de Señales) y la identificación con el ser Surdo se caracterizan de forma positiva, pues se contraponen a la visión de la sordera como deficiencia. 


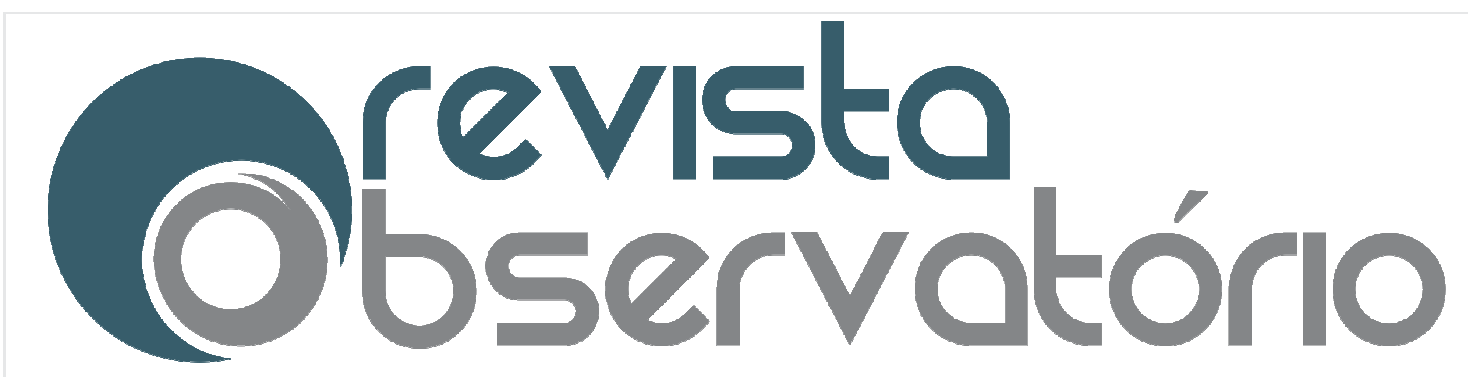

ISSN n² 2447-4266

Vol. 3, n. 4, Julho-Setembro. 2017

DOI: http://dx.doi.org/10.20873/uft.2447-4266.2017v3n4p407

Finalmente, demostramos la importancia del uso de las tecnologías como medio de acceso a los conocimientos sobre la propia salud, que no siempre llegan a las mujeres Sordas a partir de los profesionales de la salud.

PALAVRAS CLAVE: Mujeres Sordas; LIBRAS; Tecnologías; Accesibilidad.

Recebido em: 28.02.2017. Aceito em: 23.05.2017. Publicado em: 01.07.2017 


\section{Observisto}

ISSN n² $2447-4266$

Vol. 3, n. 4, Julho-Setembro. 2017

DOI: http://dx.doi.org/10.20873/uft.2447-4266.2017v3n4p407

\section{Introdução}

As tecnologias de informação e comunicação (TICs) estão presentes em todas as áreas do conhecimento humano, inclusive a da saúde. A disseminação do uso da internet vem proporcionando um crescimento acentuado do acesso à informação com benefícios para a aquisição de informações sobre doenças. Esse fenômeno não envolve somente uma mudança tecnológica, mas também mudanças econômicas, organizacionais, sociais e culturais que vêm ocorrendo desde as últimas décadas. De acordo com Lupiáñez-Villanueva (2011), estamos em um período de transição de uma sociedade industrial para uma sociedade em rede.

Em conformidade a esse cenário, o presente estudo ${ }^{5}$ discute o uso da internet como ferramenta de acesso aos conhecimentos sobre a saúde da mulher, com o foco em um grupo de mulheres Surdas ${ }^{6}$ de classe popular que não estão cadastradas no sistema local de saúde (Estratégias de Saúde da Família - ESFs), em uma cidade da Zona da Mata Mineira. Para isso, realizamos a pesquisa entre os anos de 2013 e 2015, a fim de compreender como essas mulheres Surdas, fluentes em Língua Brasileira de Sinais (LIBRAS), usufruem da

\footnotetext{
${ }^{5}$ Este artigo é um recorte da pesquisa intitulada: "Direitos Sexuais e Reprodutivos das Mulheres Surdas de Classes Populares: corporalidade e agency nas interac,ões cotidianas com as ESF's em uma cidade na Zona da Mata Mineira", que foi financiada pela FAPEMIG, Edital 01/2013, sendo concluída no final do ano de 2015.

${ }^{6}$ Conforme Padden \& Humphries (2006), a utilização da palavra Surda, com a letra S em maiúscula, ocorre para a denominação daquelas pessoas que se consideram culturalmente diferentes e que utilizam a LIBRAS como primeira língua. Ressaltamos, também, que a denominação de "cultura Surda", "comunidade Surda", além das relações estabe- lecidas entre língua e cultura são adotadas a partir de um sentido êmico, ou seja, levando em consideração a própria descrição e autodenominação das mulheres que participaram da pesquisa.
} 


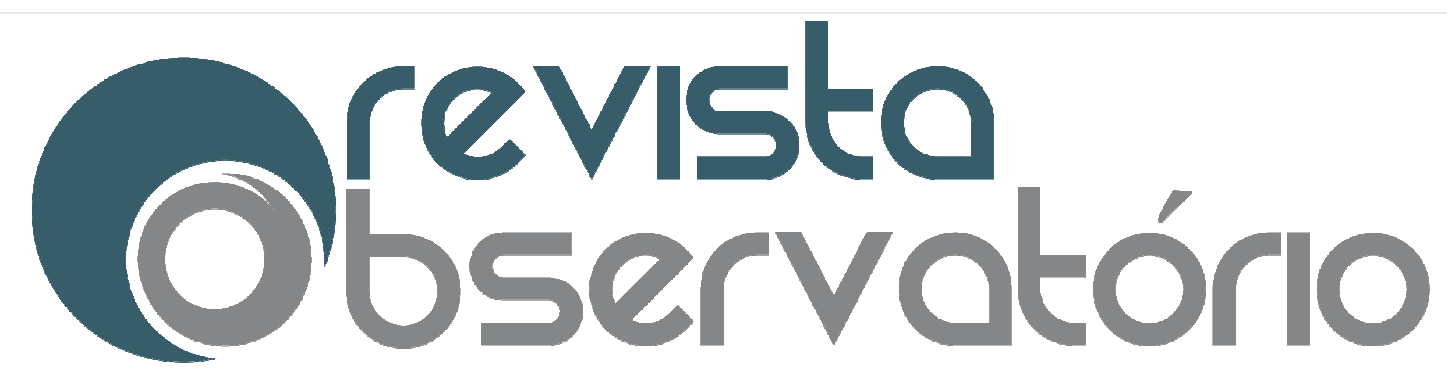

ISSN n² $2447-4266$

Vol. 3, n. 4, Julho-Setembro. 2017

DOI: http://dx.doi.org/10.20873/uft.2447-4266.2017v3n4p407

internet para adquirir informações acerca de sua saúde e difundir sua língua e cultura.

\section{A etnografia virtual}

A etnografia virtual foi primordial para a coleta e a análise dos dados, uma vez que ela incorpora as técnicas da etnografia, voltadas ao estudo de comunidades e culturas. Essas técnicas facilitam a observação e o acompanhamento de pessoas ou grupos a partir do contato e comunicação online/off-line, por meio do uso de computadores (KOZINETS, 1998). Quando aplicada às redes sociais para a obtenção de informação das mulheres Surdas, a etnografia analisa a inclusão social em redes temáticas na web, compreendendo-as como contexto e mecanismo cultural, visando captar o desempenho da comunidade de aprendizagem. Além disso, fornece ferramentas para analisar comportamentos e atitudes dos atores da sociedade em rede (PASSARELLI et al, 2010).

A partir da etnografia virtual foi possível observar as interações mediadas pelas ferramentas comunicacionais, como chats, Facebook, mensagens de texto via celular e redes sociais, e-mail, sites. Para Mercado (2012: 175):

\footnotetext{
A observação baseia-se na leitura das mensagens enviadas aos espaços virtuais (fórum, chat, lista de discussão), apresentações pessoais, disponibilidade e tema e a leitura de mensagens dos grupos. Os grupos selecionados representaram níveis de interação diferentes. Critérios utilizados: qualidade das relações estabelecidas entre eles; número de mensagens; valorizações e indicações realizadas para consulta; e atitude diante dos problemas que surgiram no grupo.
}

$\mathrm{Na}$ etnografia virtual o pesquisador mescla a observação com a participação, sendo agente principal da pesquisa. A intensidade da participação do pesquisador é variável de acordo com tipo de estudo, alternando o 


\section{Observisto}

ISSN n² 2447-4266

Vol. 3, n. 4, Julho-Setembro. 2017

DOI: http://dx.doi.org/10.20873/uft.2447-4266.2017v3n4p407

pesquisador no papel de observador e, em outras vezes, de participante das interações nos ambientes virtuais. O objetivo da observação participante é desnudar os encontros que permeiam o dia a dia da prática on-line, descrever as ações e representações de seus atores sociais e entender os significados que são criados e recriados no cotidiano virtual (idem).

No decorrer da pesquisa, observou-se a necessidade de adentrar neste campo, visto que as mulheres Surdas usufruíam das tecnologias como meio de sociabilidade e de aquisição de conhecimentos. Desse modo, percebe-se que diversos conhecimentos a respeito da saúde, que eram veiculados através de imagens e vídeos, estão disponíveis na internet, tornando conhecimentos que antes eram inacessíveis, disponíveis, como os direitos sexuais e reprodutíveis. Porém, ao mesmo tempo, a internet também evidencia o desafio de regular a qualidade das informações e o tipo de interpretações que são feitas a partir do conteúdo apresentado como meio de aprendizagem acerca da saúde.

Outro ponto a ser considerado surge em decorrência da rápida evolução do contexto on-line, trazendo instabilidade ao status dos profissionais. É importante entender como os usuários decidem no que devem acreditar, especialmente no que se refere à implantação de cuidados de saúde e informações (O'GRADY, 2010). Neste ponto a etnografia virtual permite não apenas a investigação da maneira como as pessoas utilizam a internet, mas também possibilita compreender como essa busca torna a internet e o meio virtual significativos em contextos locais (MERCADO, 2012).

Desse modo, vários dados apresentados na pesquisa advêm das redes sociais, seja através de postagens de imagens públicas nas redes sociais ou do diálogo nos chats sobre os temas da pesquisa, os quais eram abordados durante as observações participantes. Estes dados demonstraram que havia uma reflexão e uma busca por respostas posteriores aos encontros com as 


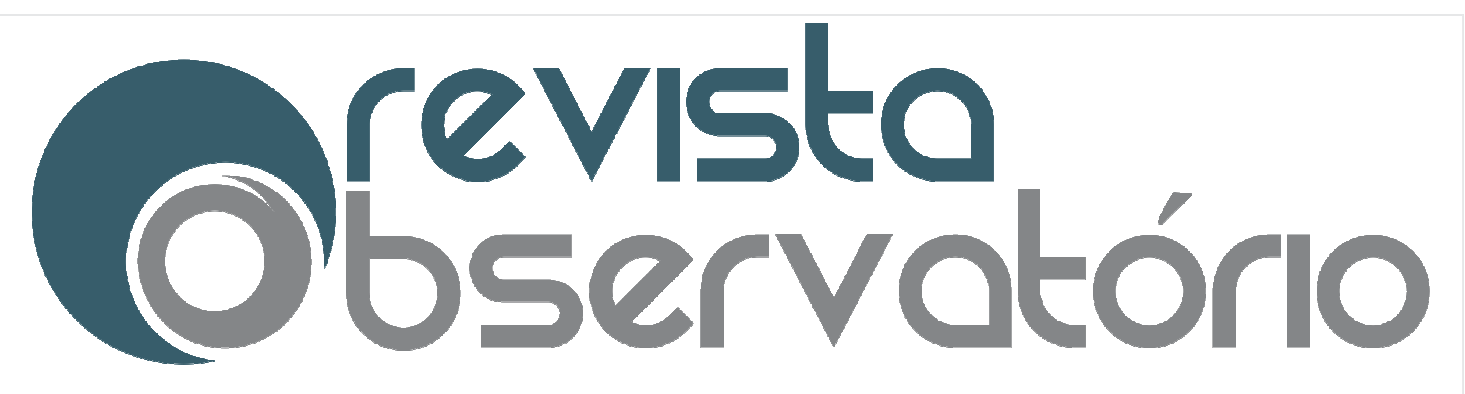

ISSN n² 2447-4266

Vol. 3, n. 4, Julho-Setembro. 2017

DOI: http://dx.doi.org/10.20873/uft.2447-4266.2017v3n4p407

pesquisadoras. Durante as interações, muitas vezes, as respostas não eram dadas naquele momento. No entanto, percebíamos que as conversas e questionamentos levavam a postagens virtuais que, geralmente, respondiam às nossas perguntas.

\section{Trajetórias da pesquisa}

A pesquisa acompanhou as trajetórias de mulheres Surdas de uma cidade da Zona da Mata Mineira, com idade entre 18 e 60 anos, que utilizam a LIBRAS como meio de comunicação. Partimos de pequenas entrevistas com professores, estudantes e intérpretes da Universidade local que possuíam algum tipo de relação com pessoas Surdas, geralmente através do ensino de LIBRAS. Dessa forma, esses contatos se configuraram como uma espécie de sistema de indicações interpessoais que, gradativamente, formaram uma rede de contatos que identificou ao total oito mulheres Surdas usuárias da LIBRAS, moradoras da zona urbana da cidade, que não estão cadastradas em alguma das 15 Estratégias de Saúde da Família (ESFs) da cidade.

À medida que se estabelecia o vínculo entre a equipe de pesquisadores $\mathrm{e}$ as mulheres foi possível traçar diálogos proveitosos sobre a saúde sexual e reprodutiva das mesmas, sendo este o objetivo central da presente pesquisa. Acompanhamos cinco das seis mulheres usuárias da LIBRAS em suas rotinas com intuito de estabelecer vínculos e dar prosseguimento ao nosso estudo. Durante esse processo observamos como se delineavam os espaços de sociabilidade dessas mulheres, tais como suas relações familiares, coletivas e individuais.

Para apresentar as participantes da pesquisa, o quadro que segue foi elaborado, demonstrando as categorias: forma de identificação utilizada no 


\section{Obevisto}

DOI: http://dx.doi.org/10.20873/uft.2447-4266.2017v3n4p407

trabalho; idade (levando em conta o ano de 2014 como referência); forma de atendimento de saúde; profissão/ocupação; meio linguístico de comunicação; autodeclaração de raça/etnia; $e$, acesso às tecnologias de informação e comunicação.

A fim de garantir sigilo absoluto e preservar a identidade das participantes, optamos por representá-las através de imagens com os sinais de letras do alfabeto em LIBRAS, indicando as iniciais de cada participante.

\begin{tabular}{|c|c|c|c|c|c|c|}
\hline \multicolumn{7}{|c|}{ Surdas Pesquisadas } \\
\hline Nome & Idade & $\begin{array}{c}\text { Recebe } \\
\text { atendimento de } \\
\text { saúde }\end{array}$ & Ocupação & $\begin{array}{c}\text { Usa a } \\
\text { LIBRAS }\end{array}$ & $\begin{array}{c}\text { Raça/etnia } \\
\text { (autodeclarada) }\end{array}$ & Utiliza TICs \\
\hline$i$ & 26 & Plano UNIMED & $\begin{array}{l}\text { Estudante/ RH - } \\
\text { Magazine Luiza }\end{array}$ & $\operatorname{Sim}$ & Branca & $\operatorname{Sim}$ \\
\hline $\boldsymbol{G}$ & 33 & Plano PLAMHUV & $\begin{array}{c}\text { Setor Cozinha - } \\
\text { HSJB }\end{array}$ & $\operatorname{Sim}$ & Branca & $\operatorname{Sim}$ \\
\hline $\boldsymbol{R}$ & 27 & SUS & Estudante UFV & Sim & Branca & Sim \\
\hline $\boldsymbol{l}$ & 43 & SUS & Dona de Casa & $\operatorname{Sim}$ & Branca & Não \\
\hline A & 26 & SUS & Estudante & Sim & Branca & Sim \\
\hline c & 25 & SUS & Estudante & Sim & Branca & Sim \\
\hline
\end{tabular}

Quadro 1: Relação das mulheres Surdas com idade entre 18 e 60 anos que compuseram o universo da pesquisa. 




O acesso a essas mulheres ocorreu de dois modos: 1) pela interação estritamente face a face, ou seja, através de acompanhamento em locais de trabalho e/ou nos trajetos urbanos percorridos no dia a dia, tal como ocorreu

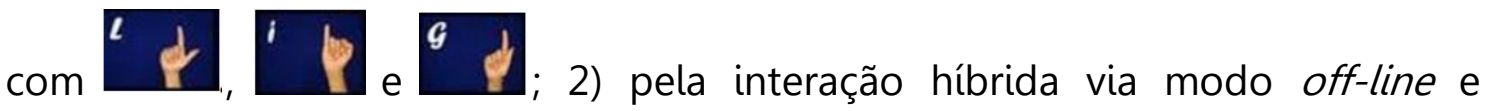
também on-line especialmente com ${ }^{\boldsymbol{R}} \boldsymbol{A},{ }^{\boldsymbol{A}} \mathrm{C}^{\boldsymbol{C}} \boldsymbol{C}$ que fazem uso ativo das TICs.

Cabe salientar que cinco mulheres se mostraram disponíveis para

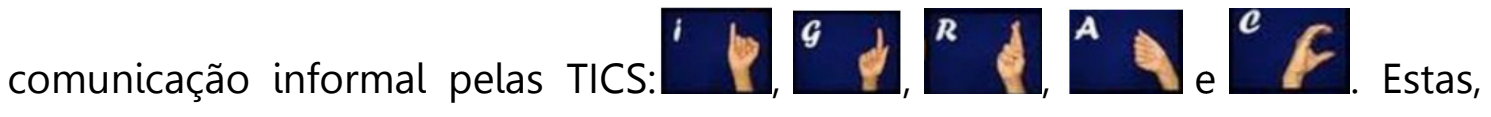
por sua vez, procuram informações e mostram maior agenciamento do corpo. Algumas delas inclusive mandavam reportagens e imagens acerca dos temas abordados neste trabalho como, por exemplo, saúde sexual e reprodutiva, por mensagens via rede social Facebook para um dos pesquisadores que mantinha contato virtual com as mesmas.

\section{A inserção linguística e a saúde da mulher Surda}

A língua é um importante fator social e cultural a ser considerado no que diz respeito a garantia de direitos humanos. Essa prerrogativa também se aplica em relação à saúde da mulher Surda, pois a LIBRAS é essencial para que haja interação entre os sujeitos envolvidos no atendimento médico, além de possibilitar a construção identitária dentro da comunidade Surda. Portanto, o uso da Língua de Sinais é a forma mais viável de inserir e integrar efetivamente o Surdo na sociedade (GEDIEL, 2010).

Porém, nos deparamos com a problemática da barreira linguística entre Surdos e ouvintes, pois, a partir de dados levantados na pesquisa, os próprios 


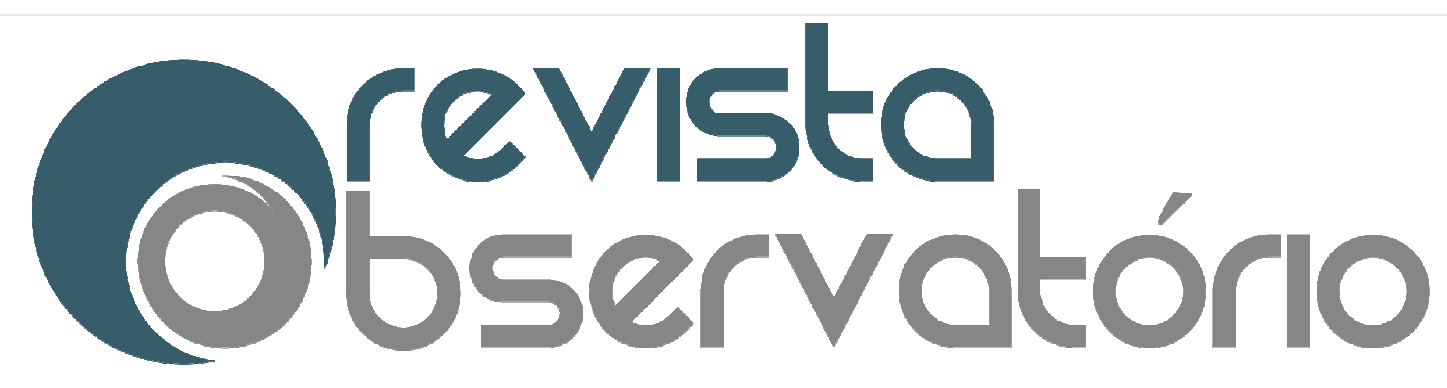

ISSN n² 2447-4266

Vol. 3, n. 4, Julho-Setembro. 2017

DOI: http://dx.doi.org/10.20873/uft.2447-4266.2017v3n4p407

profissionais de saúde justificam a dificuldade de atendimento à mulher Surda por não conhecerem a LIBRAS.

Mesmo com a garantia de acesso universal à saúde realizada pelo Sistema Único de Saúde (SUS), sabemos que muitas mulheres Surdas não usufruem desse serviço, seja devido à falta de divulgação ou à dificuldade de

comunicação. Podemos perceber a veracidade dessa afirmação quando

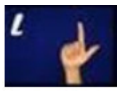
nos relatou que precisa de intérprete para se comunicar em todos os serviços de saúde que procurava, porém eles não ofereciam a acessibilidade requisitada. Por conta disso, ela precisava levar suas filhas ouvintes e bilíngues (são fluentes em LIBRAS e em Língua Portuguesa), para interpretar a comunicação entre a mãe e os profissionais da saúde, efetivando o atendimento. Essa questão nos leva a refletir acerca de considerações éticas: suas filhas são crianças e estão expostas à responsabilidade de atuação profissional, como o ato de interpretar uma consulta médica; a paciente Surda sofre constrangimento ao expor questões de saúde sexual e reprodutiva, consideradas íntimas, na presença de suas filhas e pelo intermédio delas. Além disso, os termos utilizados e a forma de expressão no momento da interpretação podem ocorrer de forma distorcida, visto que as crianças ainda não possuíam conhecimento técnico sobre a sexualidade da mulher, o qual, geralmente, é tratado a partir da adolescência como exemplo citamos as decisões referentes aos métodos contraceptivos esse tipo de situação interfere diretamente na qualidade da consulta médica.

Podemos perceber como a comunicação com Surdos é um desafio para os profissionais da saúde, prejudicando o vínculo com os pacientes e o atendimento a eles oferecidos. Ademais, uma parcela significativa da população Surda pertence às classes socioeconômicas mais baixas, limitando, dessa forma, o acesso à informação. Reconhecer as fragilidades na comunicação em situação 


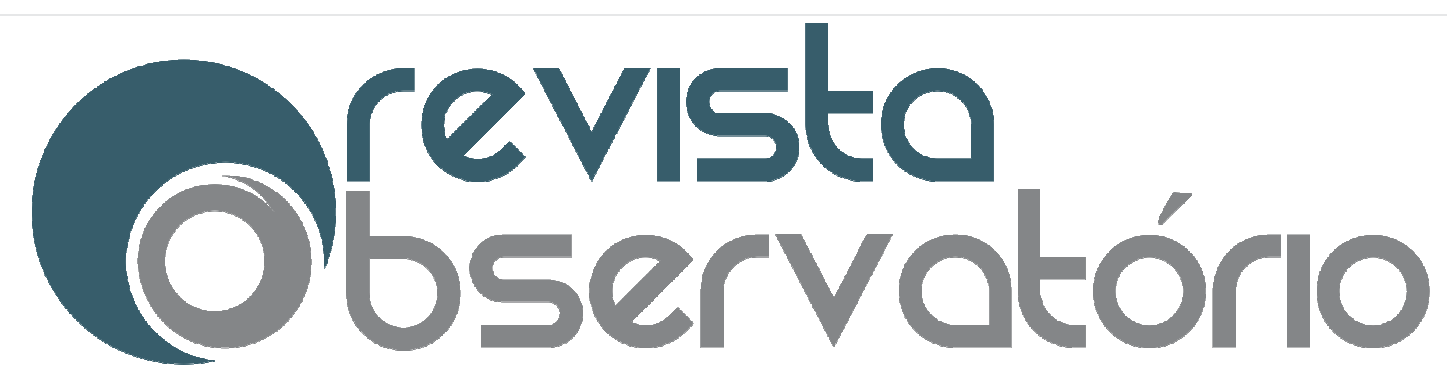

de cuidado à saúde faz com que os profissionais reflitam acerca dessas questões buscando a melhoria de seus serviços (FREIRE et al, 2009).

Uma dessas melhorias encontra-se na comunicação através de sinais, mostrando-se fundamental na assistência aos pacientes Surdos, permitindo a qualidade do cuidar, conforme afirma Silva e Silva (2004: 212): "o profissional que reconhece a [LIBRAS] adequadamente remete significado aos sinais potencializando suas interações", logo, o profissional que domina a língua de seu paciente fortalece o diálogo, garantindo um atendimento de qualidade.

Segundo Santana \& Bergamo (2005), o movimento Surdo e a constituição de uma luta política em busca da visibilidade como cultura e identidade Surdas têm trazido o reconhecimento de suas diferenças em contraposição ao conceito de deficiência. O principal elemento de afirmação cultural e identitário é a LIBRAS, a língua específica da comunidade Surda brasileira. Nesse sentido, ${ }^{c} C$ evidencia em sua página de rede social a LIBRAS como um elemento positivo e, ao mesmo tempo, denuncia o preconceito em relação ao uso dessa língua, conforme postagem que segue:

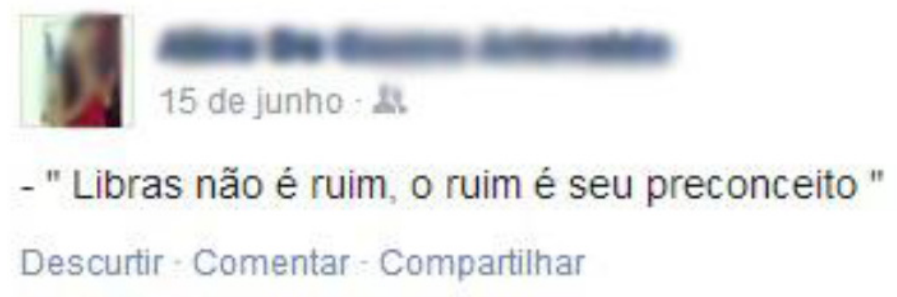

Figura 1 - postagem de C sobre preconceito linguístico referente à Língua de Sinais.

Como referenciado acima, o componente linguístico é um importante elemento para compreender a cultura surda e suas peculiaridades. Desde o século XX, nos Estados Unidos, estudos linguísticos a respeito da estrutura 


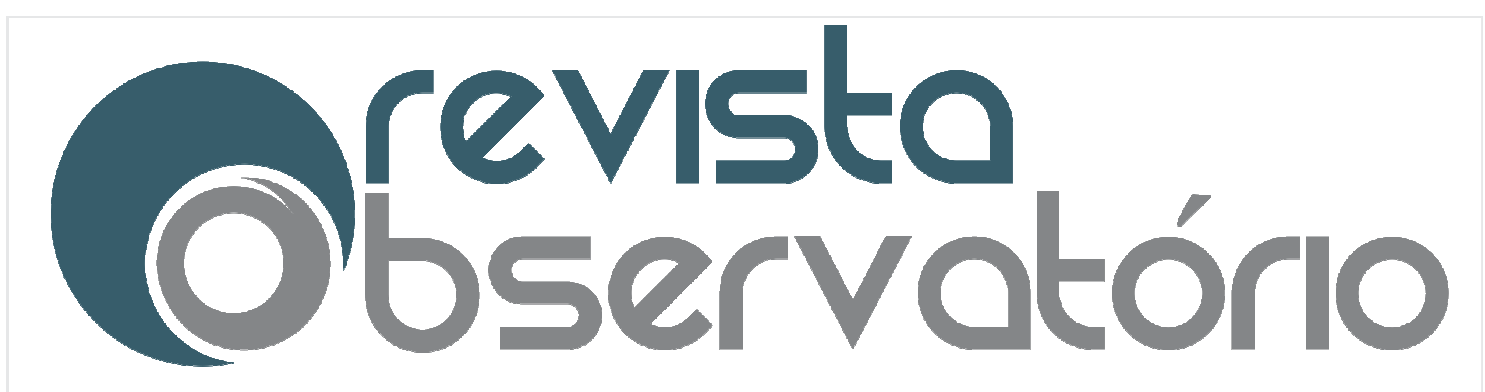

gramatical das línguas de sinais vêm sendo desenvolvidos (STOKOE, 1960; PADDEN \& HUMPHRIES, 1988). Isso possibilitou, posteriormente que os pesquisadores brasileiros pudessem desenvolver pesquisas acerca da Língua de Sinais no Brasil. Entretanto ela só recebeu reconhecimento legal através da Lei no 10.436, no dia 24 de abril de 2002 (BRASIL, 2002).

A LIBRAS é considerada uma língua natural, possuindo a mesma complexidade linguística de qualquer outra língua, oral ou gestual, como a Língua Portuguesa, Francesa ou Inglesa (GESSER, 2009). Logo, a LIBRAS atende a todos os critérios linguísticos necessários ao reconhecimento de uma língua natural, tanto no léxico, na sintaxe e na possibilidade de elaborar uma quantidade infinita de sentenças (QUADROS \& KARNOPP, 2004). Sendo assim, compreende-se que a LIBRAS, embora historicamente jovem, pode ser considerada um recurso indispensável no processo de interação médicopaciente, visto que é a língua utilizada para a comunicação, expressão e entendimento da maioria das pessoas Surdas ${ }^{7}$.

É essencial que o profissional da saúde compreenda os traços culturais da pessoa Surda, pois segundo Madeleine Leininger (1991), o cuidado em saúde deve ser cultural, ou seja, deve considerar, primeiramente a especificidade linguística do paciente Surdo, que norteará todo o atendimento.

\footnotetext{
${ }^{7}$ Nos referimos aqui, em específico, às pessoas Surdas identificadas a partir do uso da letra $\mathrm{S}$ maiúscula. Ou seja, a maioria das pessoas que se consideram pertencentes à uma cultura específica, que compartilha o uso da Língua de Sinais como principal meio de expressão e comunicação. Essas pessoas prezam pelo atendimento na sua própria língua. Muitas delas não são oralizadas e a Língua Portuguesa escrita é considerada segunda língua.
} 


\section{Observisto}

\section{O acesso às informações sobre saúde via Tecnologias de Informação e Comunicação - TICs}

Ao longo das observações participantes desta pesquisa, outros rumos, discursos e práticas foram delineando-se. O acompanhamento contínuo das mulheres fluentes em LIBRAS nos permitiu delimitar nossas pesquisadas, verificar a inserção dessas sujeitas no mundo ouvinte, especialmente no que diz respeito à aquisição de informações sobre a saúde.

Percebemos a partir do segundo ano de pesquisa que a participação nas redes sociais compõe uma esfera importante no campo de interações e agência dessas mulheres Surdas, principalmente em locais de menor organização política ou de inexistência de instituições auto-organizadas que legitimam as sociabilidades e o empoderamento da mesma. As interações on-line ocupam, portanto, um lugar considerável de participação de algumas pessoas surdas na vida pública e na obtenção de informações referentes à saúde.

A internet, portanto, apresenta-se não apenas como uma simples ferramenta de socialização, mas como mais uma possibilidade de alargamento do contato entre pessoas Surdas e ouvintes, viabilizando maior democratização do acesso às informações e ao conhecimento, antes exclusivo aos ouvintes.

Para Lévy (1993) a potencialidade da informática recai exatamente no fato dela ser uma tecnologia aberta à novas conexões inesperadas, possuindo o potencial de transformar de forma radical seus significados e usos planejados inicialmente. É nesse fato que repousa a bem-sucedida performance ${ }^{8}$ das pessoas Surdas no meio virtual, em especial, nas redes sociais e na obtenção de

\footnotetext{
${ }^{8}$ Consideramos as ações performativas no sentido do conceito de programa de Gilles Deleuze e Félix Guattari discorrido no texto "Como criar para si um corpo sem órgãos" no qual o programa é um acionador da experiência, um "motor da experimentação" (DELEUZE \& GUATTARI, 1999, p. 12).
} 


\section{Observisto}

informações. No universo das pessoas Surdas, o uso de imagens contribui no desenvolvimento cognitivo, devido às características da modalidade visuoespacial da LIBRAS (GESSER, 2009).

Através das TICs, os diferentes atores que compõe o sistema de saúde profissionais, gestores e pacientes - podem usar a internet como fonte de informações, meios de comunicação e até mesmo ferramenta para a prestação de serviços, tornando a internet uma área para a saúde pública. Esta gama de possibilidades tem um enorme potencial para modificar a prática de cuidados de saúde com base na troca virtual de informações. No entanto, deve-se levar em conta a qualidade da informação disponível na internet, como ela é utilizada por esses atores e os possíveis efeitos da mesma sobre a relação entre profissional-paciente.

As informações relacionadas à saúde atualmente são difundidas e bastante populares em websites interativos, portais, e-mails, aplicações de telessaúde, comunidades on-line, jogos e simuladores. Pacientes coletam informações fora da interação face a face com os profissionais de saúde, o que torna possível o retorno ao "diagnóstico" quantas vezes forem necessárias, descentralizando e democratizando o acesso à informação. Conforme Bastos e Ferrari (2011), esses são pontos positivos das TICs no que diz toca à facilidade no acesso à informação. Além do que foi exposto, a internet também pode ser observada como fonte de informação e meio de comunicação para melhorar a relação profissional-paciente, já que ambos podem compartilhar seus conhecimentos sobre uma determinada patologia ou condição de saúde, melhorando dessa forma a comunicação e tornando as decisões mais eficientes (LUPIÁÑEZ-VILLANUEVA, 2011).

A utilização da internet para obtenção de informações, apesar de promissora, não deve ser utilizada sem planejamento e avaliação. As TICs 


\section{Observistotório}

DOI: http://dx.doi.org/10.20873/uft.2447-4266.2017v3n4p407

devem ser utilizadas para dar suporte aos atendimentos em saúde e não como a única fonte de obtenção de conhecimento sobre a saúde (BASTOS e FERRARI, 2011).

Podemos exemplificar esta afirmação com a seguinte situação: durante a pesquisa, quando era indagadas acerca dos direitos sexuais e reprodutivos, em

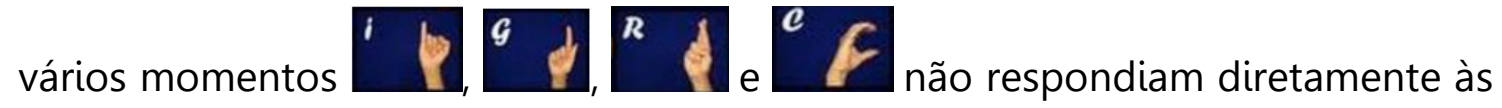
perguntas. Posteriormente, elas enviavam, através das redes sociais, imagens e/ou pequenos vídeos a respeito do assunto anteriormente tratado. O uso de imagens, apesar de um forte aliado no atendimento às pessoas Surdas, pode gerar interpretações múltiplas quando são utilizados sem o devido cuidado por parte dos usuários, demonstrando um dos perigos no uso das TICS, já que imagens podem demonstrar ambivalência em seu sentido.

Observamos que as pesquisadas estavam atentas aos assuntos compartilhados em blogs e canais do YouTube, trazendo como temática assuntos sobre a saúde da mulher, como por exemplo, os métodos contraceptivos. Posteriormente elas partilhavam as informações através de suas redes sociais.

Consideramos que houve a agency ${ }^{9}$ dessas mulheres em busca dos conhecimentos sobre seus direitos sexuais e reprodutivos, que não foram

\footnotetext{
${ }^{9}$ Cunhado inicialmente por Giddens (1984), o conceito de agency é uma tentativa de sintese entre uma dualidade clássica no campo da Sociologia que se dá entre o indi-víduo e a estrutura social. Tal conceito tem uma possibilidade para o indivíduo atuar para além das sugestões estruturais; e, desse modo, poder intervir no curso dos acon- tecimentos, alterando-os dentro de certos limites, ou para além deles, o que seria mais difícil de ocorrer, Giddens (1984). Neste estudo, tal conceito será desenvolvido a partir da definicão de Alessandro Duranti, que reflete acerca da agency in language. Duranti $(2001 ; 2004)$ considera que toda fala (ou neste caso, a sinalização) envolve um tipo de "agência" da língua, em duas dimensões de ocorrência: sua realização linguística (per- formance) e sua representação linguística (codificação da língua).
} 


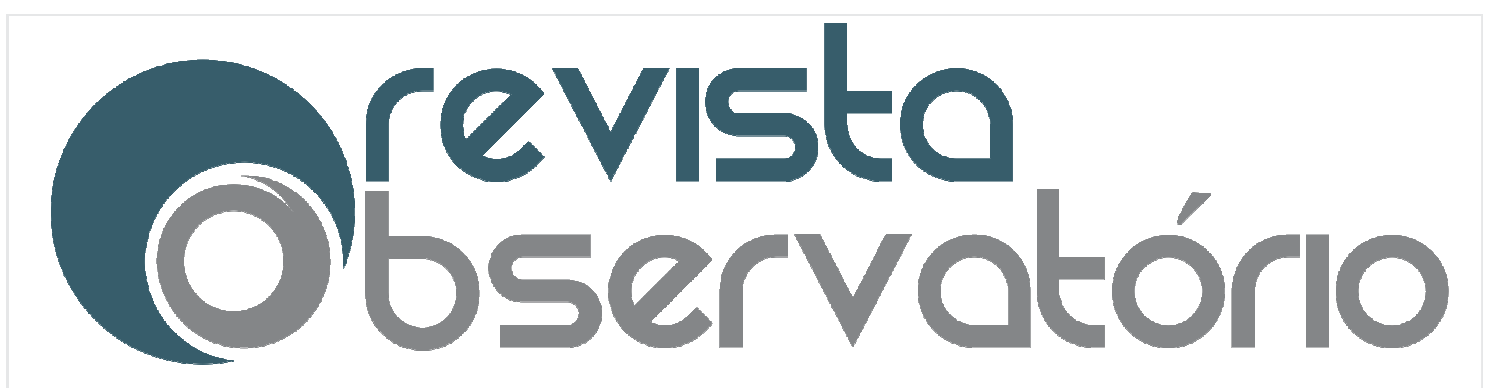

acessados através do sistema de saúde. Elas buscaram informações a partir das ferramentas virtuais para suprir a necessidade de aprendizagem. No entanto, não podemos assegurar que a interpretação por meios das imagens e vídeos encontrados na internet possuem o mesmo conhecimento que a explicação de um profissional da saúde através da LIBRAS. Em outras palavras, é possível afirmar que as participantes da pesquisa adquiriram certo nível de conhecimento via ambiente virtual; entretanto, não há certeza do que elas realmente entendam seus direitos sexuais e reprodutivos somente a partir de imagens, não garantindo o conhecimento daquilo que está descrito nos planos governamentais de políticas para mulheres ou como os pressupostos que devem ser seguidos no cotidiano do serviço de saúde.

Contudo, deve-se lembrar que a educação/acesso do paciente baseada na internet é um campo novo e crescente de pesquisa para os profissionais de saúde. Ela deve ser utilizada como forma de complementação e não de substituição da educação fornecida de forma presencial.

\section{Considerações Finais}

Dar visibilidade às mulheres Surdas e investigar sobre o acesso aos setores públicos da cidade foram esforços imbuídos a partir das relações e dos significados construídos durante as experiências de comunicação com esse segmento. Esse convívio trouxe importantes questionamentos tanto para as pesquisadas quanto para as pesquisadoras. As pesquisadas refletiram em inúmeros momentos sobre questões que nunca haviam sido despertadas, assim como as pesquisadoras puderam conhecer um universo complexo de um grupo minoritário, refletindo sobre o acesso à saúde a real inclusão das pessoas Surdas e a efetividade das atuais políticas públicas. 


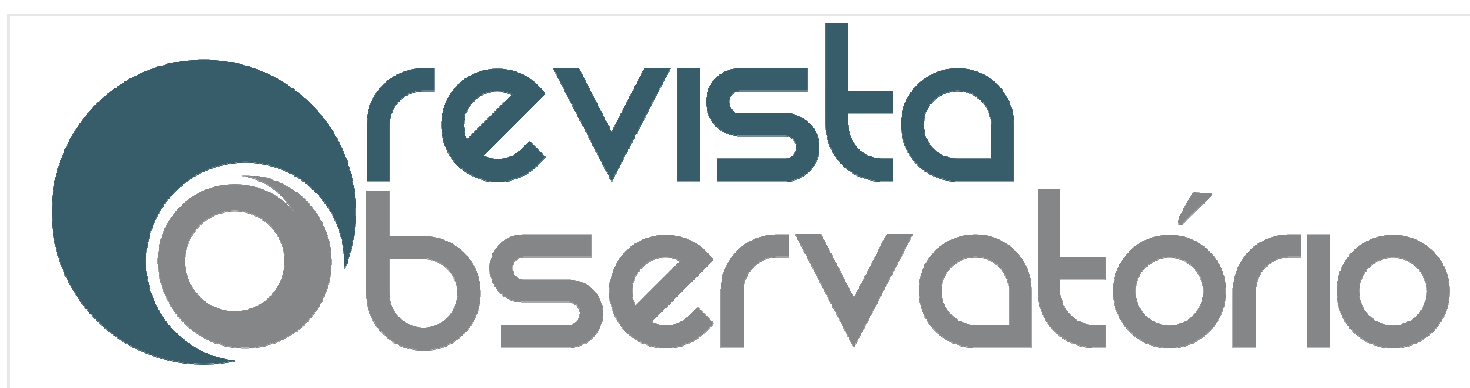

ISSN n² 2447-4266

Vol. 3, n. 4, Julho-Setembro. 2017

DOI: http://dx.doi.org/10.20873/uft.2447-4266.2017v3n4p407

A falta de focalização do grupo em campanhas de saúde e prevenção contra doenças sexualmente transmissíveis, a descentralização para a obtenção de conhecimentos a partir de meios de comunicação exclusivamente para ouvintes e a dificuldade de trocas linguísticas fazem com que as mulheres Surdas, de classes populares, não tenham acesso ao conhecimento devido, geralmente, à impossibilidade de incluírem-se efetivamente nos sistemas atuais de saúde. É nesse sentido que a redefinição de saúde sexual e reprodutiva, de acordo com as Políticas para as Mulheres, serve para projetar uma série de iniciativas no âmbito dos direitos humanos que são estabelecidos a partir de universos particulares, conforme os grupos e instituições em questão, dentre elas o conjunto de mulheres Surdas da cidade.

Chamamos a atenção para a especificidade de comunicação em LIBRAS e a necessidade de atendimento adequado às pessoas Surdas, tanto no que diz respeito ao acesso ao atendimento, como nas campanhas de prevenção e no planejamento das visitas dos agentes comunitários de saúde, ou seja, no atendimento proposto pelas ESFs.

O acesso à comunicação torna-se, consequentemente, uma questão de vulnerabilidade não só no âmbito da saúde coletiva, mas na vida social cotidiana. O sistema público de saúde é entendido como um meio fundamental de atendimento a esse segmento de mulheres na busca da integralidade e da promoção da saúde.

A partir das investigações realizadas através das tecnologias de informação, averiguamos a presença de um reforço da construção identitária através da LIBRAS, não só no que tange o universo das relações sociais, mas também a assuntos relacionados à saúde.

Nesse contexto as tecnologias surgem como uma facilidade na obtenção de informações de saúde, até mesmo complementando o atendimento às 


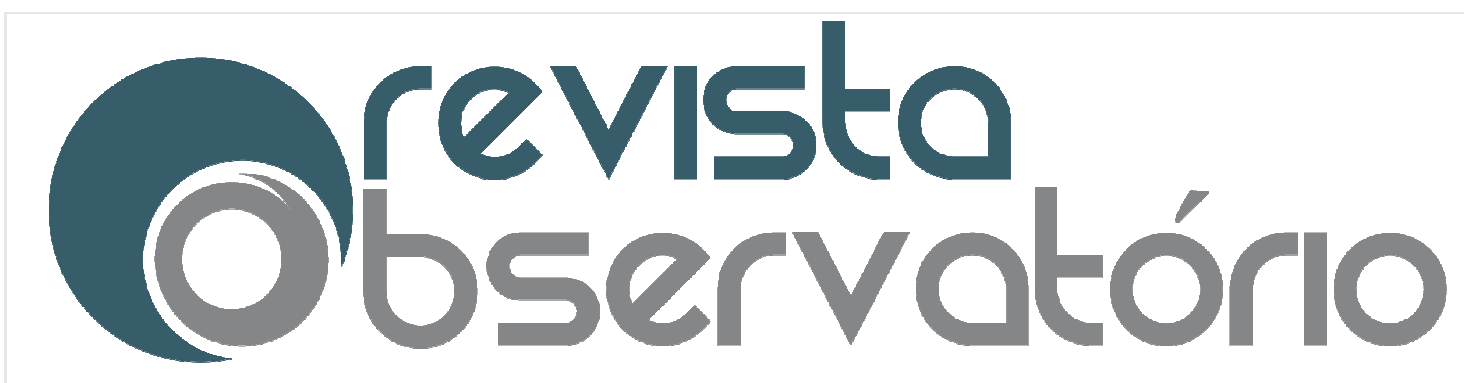

mulheres Surdas. Contudo, não podemos deixar de ressaltar a importância de confirmar a veracidade do que é obtido na rede e do entendimento efetivado pelas mulheres, uma vez que as imagens podem gerar duplo sentido interpretativo para as informações que estão sendo transmitidas.

A partir desse conjunto de questões que foram averiguadas, entendemos a importância da visibilidade e reconhecimento das necessidades de melhoria das condições de vida e de saúde das mulheres Surdas que se encontram em condições vulneráveis principalmente devido à barreira linguística.

\section{Referências}

BASTOS, B.G.; FERRARI, D. V. Internet e educação ao paciente. Intl. Arch. Otorhinolaryngol., São Paulo - Brasil, v.15, n.4, p. 515-522, Out/Nov/Dezembro 2011.

BRASIL. Lei no 10.436 de 24 de abril de 2002, que dispõe sobre a Língua Brasileira de Sinais - LIBRAS, e dá outras providências. Publicada no Diário Oficial da União em de 24 de abril de 2002.

DURANTI, Alessandro. The scope of Linguistic Anthropology. In: Linguistic Anthropology. New York, NY: Cambridge University Press, 1997. (Org.).

Linguistic Anthropology: A reader. Oxford: Blackwell Publish- ing Ltd, 2001.

. (Org.). A Companion to Linguistic Anthropology. Malden, Mass.: Blackwell, 2004. 


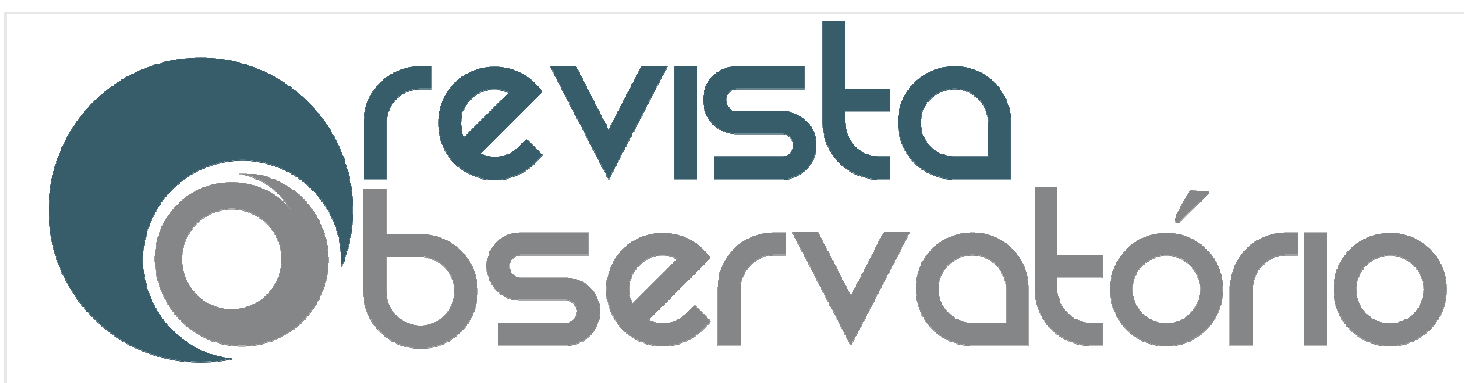

FREIRE, D. B. et al. Acesso de pessoas deficientes auditivas a serviços de saúde em cidade do Sul do Brasil. Cad. Saúde Pública, Rio de Janeiro, 25(4):889-897, abril, 2009.

GEDIEL, A. L. B. Saúde e Doença: os significados de família e reprodução das mulheres surdas de Porto Alegre, RS. In: Fazendo Gênero 9: Diásporas, diversidades, deslocamentos, 2010, Florianópolis. Anais Fazendo Gênero. Florianópolis: Fazendo Gênero 9, 2010. Disponível em:

<http://www.fazendogenero.ufsc.br/9/resources/anais/1277942265 ARQUIVO T rabalhocompletoFazendoGenero.pdf > . Acesso em: 09:44hs.

GESSER, Audrei. LIBRAS? Que língua é essa? Crenças e preconceitos em torno da Língua de Sinais e da realidade Surda. São Paulo: Parábola Editora, 2009.

GIDDENS, Anthony. The Constitution of Society. Cambridge: Polity Press, 1984.

KOZINETS, R. V. On netnography: initial reflections on consumer research investigations of cyberculture. Advances in Consumer Research, New York, v. 25, p. 366-371, 1998.

LEININGER, M. M. Culture care diversity \& universality: a theory of nursing. New York: National League for Nursing Press, 1991.

LÉVY, Pierre. As tecnologias da inteligeńncia. Rio de Janeiro: Ed. 34, 1993. 


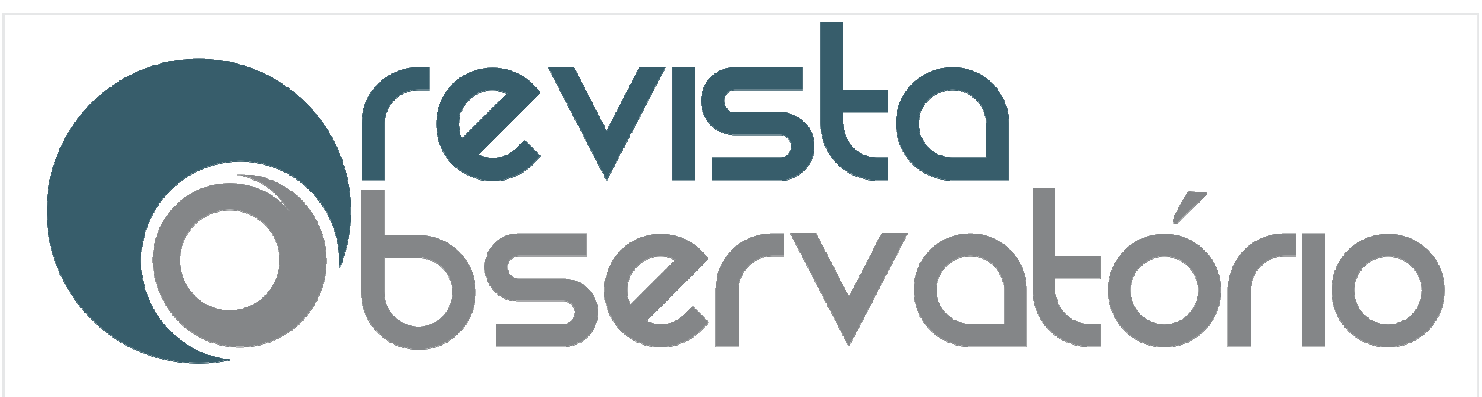

LUPIÁÑEZ-VILLANUEVA, F. Health and the Internet: Beyond the Quality of Information. RevEspCardiol.2011;64:84950, 2011.

MERCADO. L.P.L. Pesquisa qualitativa online utilizando a etnografia virtual. Revista Teias v. 13 n. 30; 169-183 set./dez. 2012.

O'GRADY, L. Sensemaking and Credibility of Health Informationin Online Message Forums: A Multi-Method Study Assessing Tagging and Tag Clouds. CSCW 2010, February 6-10, 2010, Savannah, Georgia, USA.

PADDEN, C.; HUMPHRIES, T. Deaf in America - Voices from a culture.Cambridge: Harvard University Press, 1988.

PASSARELLI, B. O OBSERVATÓRIO DA CULTURA DIGITAL: A NOVA LINHA DE PESQUISA DA ESCOLA DO FUTURO DA USP. São Paulo, maio/2010.

QUADROS, Ronice M. de. \& KARNOPP, Lodenir. Língua de Sinais Brasileira Estudos Linguísticos. Porto Alegre: Artmed, 2004.

SILVA, M. F.; SILVA, M. J. P. A auto-estima e o não-verbal dos pacientes com queimaduras. RevEscEnferm USP 2004; 38(2):206-16.

STOKOE, William C. Sign Language Structure. Silver Spring: Linstok Press, 1960. 